\title{
A Comparison of the Physicochemical Properties and Fatty Acid Composition of Indaiá (Attalea dubia) and Babassu (Orbignya phalerata) Oils
}

\author{
Bianca Silva Ferreira, Lara Pereira Faza, and Mireille Le Hyaric \\ Departamento de Química, Instituto de Ciências Exatas, Universidade Federal de Juiz de Fora, Rua José Lourenço Kelmer, \\ s/n-Campus Universitário, Bairro Martelos, 36036-900 Juiz de Fora, MG, Brazil
}

Correspondence should be addressed to Mireille Le Hyaric, mireille.hyaric@ufjf.edu.br

Received 11 October 2011; Accepted 5 January 2012

Academic Editor: Fengrui Song

Copyright ( $\odot 2012$ Bianca Silva Ferreira et al. This is an open access article distributed under the Creative Commons Attribution License, which permits unrestricted use, distribution, and reproduction in any medium, provided the original work is properly cited.

The physicochemical properties and fatty acid composition of Attalea dubia (Mart.) Burret (indaiá) seed oil were investigated. The oil was extracted in a soxhlet apparatus using petroleum ether and evaluated for iodine, acid, peroxide, ester, and saponification values. The oil was also analyzed using infrared and nuclear magnetic resonance spectroscopy. The fatty acid profile of the oil was determined by GC-MS. For each analysis indaiá oil was compared to Orbignya phalerata (babassu) oil. The two oils appeared to be very similar in their fatty acid composition, in which lauric acid (the most abundant), myristic acid, caprylic acid, and capric acid were the four main fatty acids detected. The unsaturated fatty acids content was lower for indaiá oil (5.8\%) than for babassu oil $(9.4 \%)$. The results suggest that indaiá palm tree could be cultivated as a new source of vegetable oil with potential for food and cosmetic industries.

\section{Introduction}

Oils extracted from plants are important not only for their application in food, but also for their industrial applications, such as the production of biodiesel, pharmaceuticals, cosmetics, paints, and others. Attalea dubia (Mart.) Burret, also known as Bacuau palm or indaiá, is a palm tree of the Attalea species (Arecaceae) [1] endemic to the atlantic rainforest of Brazil. The tree can reach 20 meters high, with a $20-35 \mathrm{~cm}$ diameter. Its exploration for the extraction of edible palm heart is mainly illegal [2], as this tree is not a cultivated palm and has been forbidden during the last years in several states of Brazil, due to the importance of indaiá in the alimentation of wild animals [3]. The numerous bark oblong fruits (approximately $6 \mathrm{~cm}$ ) which look like small coconuts and remind babassu kernels (Orbignya phalerata) contain one or two seeds with a white oily endosperm. The oil, produced in local communities from the almonds, can be used to cook.
The physicochemical characterization of the oil, obtained from the seeds of Attalea dubia to the best of our knowledge, has not been reported yet. The objective of this work was the determination of the physicochemical properties, NMR spectra and fatty acid profiles of seed oil extracted from Attalea dubia, and their comparison with babassu oil, a common vegetable oil used in Brazil [4].

\section{Materials and Methods}

2.1. Seed Material. Mature seeds, collected in January 2011 from one palm tree in Itamarati de Minas (Brazil), were handpicked to eliminate the damaged ones. The hard shell was broken, and the seeds were manually ground.

2.2. Lipid Extraction. Oil was extracted from the ground seeds in a soxhlet apparatus with petroleum ether for 4 hours. After evaporation of the solvent a yellowish limpid oil was 


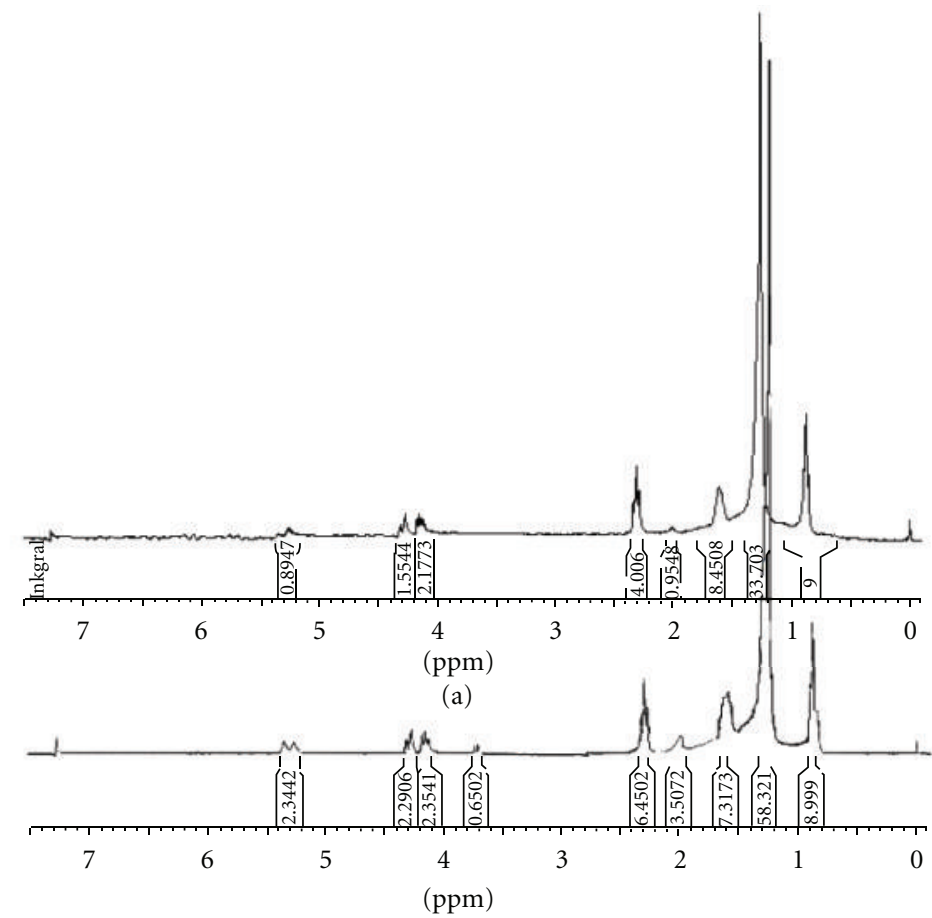

(b)

FIgURE 1: ${ }^{1} \mathrm{H}$ NMR spectra of indaiá oil (a) and of babassu oil (b) in $\mathrm{CDCl}_{3}$.

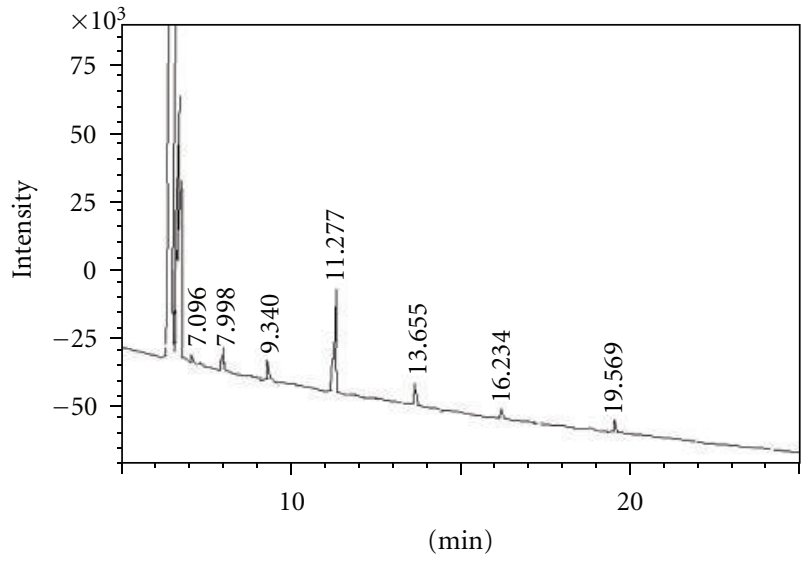

(a)

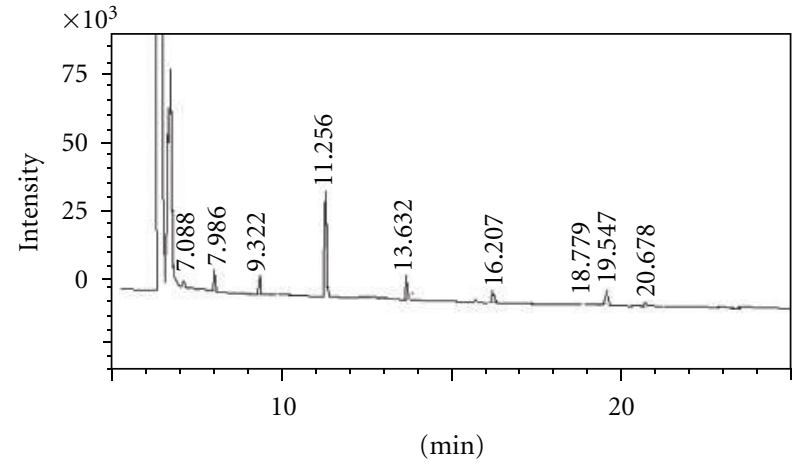

(b)

FIgURE 2: Fatty acid profiles of indaiá (a) and babassu (b) oils.

obtained (yield 15\%). Babassu oil was purchased form a local market (Januário, Brazil).

2.3. Physicochemical Analysis. The following physicochemical properties of oils were determined: density, saponification value, iodine value, peroxide value, acid values, and ester value (content, according to AOCS official methods [5]). All analysis were performed in triplicate.

2.4. Fatty Acid Profile. The fatty acid profile was determined as fatty acid methyl esters by gas chromatography-mass spectroscopy. The methyl esters were prepared using the AOCS method [6]. The separation of fatty acid esters was performed on a Shimadzu Gas Chromatograph GC-2010 with a Restek RTX-2330 capillary column $(60 \mathrm{~m} \times 0.25 \mathrm{~mm} \times$ $0.2 \mathrm{~mm}$ ). The column temperature was programmed at $130^{\circ} \mathrm{C}$ for $10 \mathrm{~min}$, then increased to $230^{\circ} \mathrm{C}$ at $5^{\circ} \mathrm{C} / \mathrm{min}$ with a final isothermal period of $13 \mathrm{~min}$. Hydrogen was used as carrier gas with constant linear velocity of $25 \mathrm{~cm} / \mathrm{sec}^{-1}$. The injector temperature was set at $250^{\circ} \mathrm{C}$, with a split ratio of $1: 10$. The flame ionization detector temperature was $250^{\circ} \mathrm{C}$. Fatty acid methyl esters (FAMEs) were identified by comparison of retention times with authentic standards (Supelco 37 comp. FAME mix $10 \mathrm{mg} / \mathrm{mL}$ in $\mathrm{CH} 2 \mathrm{Cl} 2$ ), and 


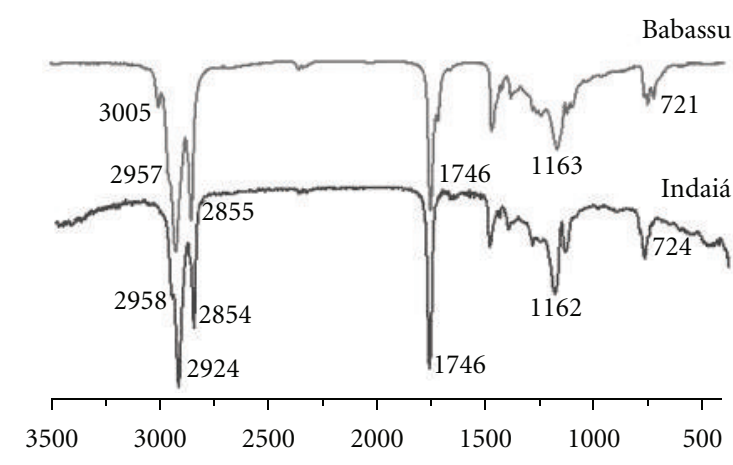

FIGURE 3: FT-IR spectra of indaiá and babassu oils.

quantification was performed by the internal normalization method.

2.5. NMR Analysis. ${ }^{1} \mathrm{H}$ spectra were acquired from a Bruker Advance DRX $300 \mathrm{MHz}$, using deuterated chloroform as solvent and trimethylsilane as internal reference $[7,8]$.

2.6. Infrared Spectrometry. FT-IR spectra of the lipid fraction of indaiá and babassu pulp were obtained on a Bomem FT IR MB- 102 spectrometer, with the samples in $\mathrm{KBr}$ pellets. The spectra were recorded in the range of $400-3500 \mathrm{~cm}^{-1}$ [9].

\section{Results and Discussion}

Indaiá oil was recovered as a yellowish liquid which solidifies when refrigerated.

3.1. Physicochemical Analysis. Usual analysis of the oil such as density, saponification value, iodine value, peroxide value, acid values, ester value, and free acid content were realized and compared to the data obtained for babassu oil [10] (Table 1).

The high saponification values of the two oils indicates a high content o triacylglycerol, consistent with the high ester value ( $>99 \%)$. No peroxide was detected in the samples, which means that they can be considered safe for to be consumed [11]. The iodine value was lower for indaiá oil than for babassu oil, suggesting that the first has a higher content of saturated fatty acid. The high saponification value indicates that Indaiá oil has potential to be used in the cosmetic industry [12]. The low acid values determined for both oils indicates that the triacylglycerols have not been hydrolyzed, which could indicate a good stability.

3.2. NMR Analysis. ${ }^{1} \mathrm{H}$ NMR spectra of both oils are illustrated in Figure 1, and their respective data are shown in Table 2.

The NMR profiles of the two oils (Table 2) were similar. The main differences were observed comparing the areas of the signals at $\sim 2 \mathrm{ppm}$ and at $\sim 5.3 \mathrm{ppm}$, corresponding respectively to the methylene an olefin hydrogens of unsaturated fatty acids and to the hydrogens at the unsaturation. Calibrating the signals of terminal methyl groups to 9 , which
TABLe 1: Physicochemical analysis of indaiá and babassu oils.

\begin{tabular}{lcc}
\hline & Indaiá & Babassu \\
\hline Density $\left(\mathrm{g} / \mathrm{cm}^{3}\right)$ & $0.917 \pm 0.003$ & $0.920 \pm 0.002$ \\
Saponification value $(\mathrm{mg} \mathrm{KOH} / \mathrm{g})$ & $240.590 \pm 0.014$ & $236.9 \pm 2.7$ \\
Iodine value $\mathrm{g}\left(\mathrm{I}_{2} / 100 \mathrm{~g}\right)$ & $7.087 \pm 0.006$ & $18.3 \pm 0.5$ \\
Peroxide value $(\mathrm{meq} / 1000 \mathrm{~g})$ & nd & nd \\
Acid value $(\mathrm{meq} / 1000 \mathrm{~g})$ & $0.677 \pm 0.006$ & $0.592 \pm 0.001$ \\
Ester value $\%$ & $99.72 \pm 0.01$ & $99.41 \pm 2.70$ \\
\hline
\end{tabular}

Nd: no peroxide was detected.

TABLE 2: ${ }^{1} \mathrm{H}$ NMR data of indaiá and babassu oils in $\mathrm{CDCl}_{3}$.

\begin{tabular}{lcc}
\hline Hydrogen nature & $\delta_{H}$ (indaiá oil) & $\delta_{H}($ babaçu oil $)$ \\
\hline $\mathrm{CH}=\mathrm{CH}$ & 5.35 & 5.34 \\
$\mathrm{CH}-\mathrm{O}$ & 5.24 & 5.26 \\
$\mathrm{CH}-\mathrm{O}$ & 4.28 & 4.31 \\
$\mathrm{CH}-\mathrm{O}$ & 4.14 & 4.27 \\
$\mathrm{CH}_{2}-\mathrm{CO}$ & 2.31 & 2.31 \\
$\mathrm{CH}_{2}-\mathrm{C}=\mathrm{C}$ & 2.01 & 2.01 \\
$\mathrm{CH}_{2}-\mathrm{CH}_{2}-\mathrm{CO}$ & 1.6 & 1.6 \\
$\mathrm{CH}_{2}$ & 1.25 & 1.25 \\
$\mathrm{CH}_{3}$ & 0.86 & 0.87 \\
\hline
\end{tabular}

would correspond to a total esterification of the glycerol, we can compare the degree of unsaturations of the two oils. The areas found at $2 \mathrm{ppm}$ were 1 (indaiá) and 3.5 (babassu), and the values found at $5.3 \mathrm{ppm}$ were 0.2 (indaiá) and 0.4 (babassu). These results are consistent with the higher iodine value of the more unsaturated babassu oil.

3.3. Fatty Acid Profile. Gas chromatography spectra of both oils are illustrated in Figure 2, and their respective fatty acid composition is detailed in Table 3.

The main fatty acids present in the two oils were lauric acid (the most abundant, representing more than $50 \%$ of the fatty acids detected in the samples), myristic acid (11\%), caprylic acid $(\sim 10 \%)$, and capric acid $(8.5 \%$ and $9.6 \%)$. Total unsaturated fatty acids represent $5.8 \%$ of indaiá oil and 9.45\% of babassu oil, which is consistent with the iodine values and with the NMR spectra of the oils.

3.4. FT-IR Analysis. FT-IR spectra of indaiá and babassu oils are illustrated in Figure 3. The assignments of their respective vibrational bands are detailed in Table 4 .

The spectra were almost identical (Figure 3), showing signals in the five main regions used for the analysis of oils and fats: (1) $3100-2805 \mathrm{~cm}^{-1}$, (2) $1770-1615 \mathrm{~cm}^{-1}$, (3) $1500-1420 \mathrm{~cm}^{-1}$, (4) $1345-1230 \mathrm{~cm}^{-1}$, and (5) 1150 $850 \mathrm{~cm}^{-1}$. The unsaturated $\mathrm{C}-\mathrm{H}$ stretching band was not detected on the infrared spectra of indaiá oil but was observed on the spectra of babassu oil. As expected no band of hydroperoxide group was observed near $3444 \mathrm{~cm}^{-1}$, confirming that none of the oils suffered oxidation [13]. The band corresponding to the triglyceride ester groups appears at $1746 \mathrm{~cm}^{-1}$, and the bands related to the stretching 
TABLe 3: Fatty acid composition (mean percentage) of indaiá and babassu oils.

\begin{tabular}{|c|c|c|c|c|}
\hline \multirow{2}{*}{ Fatty acid } & \multicolumn{2}{|c|}{ Indaiá oil } & \multicolumn{2}{|c|}{ Babassu oil } \\
\hline & $\%$ Fatty acids & Retention time (min) & $\%$ Fatty acid & Retention time (min) \\
\hline Caproic acid, $\mathrm{C}_{6}$ & 3.5 & 7.096 & 3.3 & 7.088 \\
\hline Caprylic acid, $\mathrm{C}_{8}$ & 10.9 & 7.998 & 9.2 & 7.986 \\
\hline Capric acid, $\mathrm{C}_{10}$ & 8.5 & 9.340 & 9.6 & 9.322 \\
\hline Lauric acid, $\mathrm{C}_{12}$ & 55.8 & 11.277 & 54.7 & 11.256 \\
\hline Myristic acid, $\mathrm{C}_{14}$ & 11.6 & 13.655 & 11.8 & 13.632 \\
\hline Palmitic acid, $\mathrm{C}_{16}$ & 3.8 & 16.234 & 4.8 & 16.207 \\
\hline Linoleic acid, $\mathrm{C}_{18: 2}$ & nd & nd & 0.9 & 18.779 \\
\hline Oleic acid, $\mathrm{C}_{18: 1}$ & 5.8 & 19.569 & 6.5 & 19.547 \\
\hline Stearic acid, $\mathrm{C}_{18: 0}$ & nd & nd & 2.05 & 20.678 \\
\hline Total unsaturated & 5.8 & - & 9.45 & - \\
\hline
\end{tabular}

TABLE 4: Assignments of the FT-IR bands of indaiá and babassu oil spectra.

\begin{tabular}{lccc}
\hline Region & Indaiá & Babaçu & \\
\hline 1 & - & 3005 & $(=\mathrm{C}-\mathrm{H})$ stretching \\
2 & 2958 & 2957 & $\mathrm{CH}_{3}$ asymmetry stretching \\
3 & 2924 & 2920 & $\mathrm{CH}_{2}$ asymmetry stretching \\
4 & 2854 & 2855 & $\mathrm{CH}_{2}$ symmetry stretching \\
5 & 1746 & 1746 & $\mathrm{C}=\mathrm{O}$ stretching \\
6 & 1162 & 1163 & $\mathrm{C}-\mathrm{O}$ stretching \\
7 & 724 & 721 & $\mathrm{CH}_{2}$ rocking \\
\hline
\end{tabular}

vibration of the $\mathrm{C}-\mathrm{O}$ bonding of the ester groups are observed near 1235 and $1160 \mathrm{~cm}^{-1}$.

\section{Conclusion}

The analysis of the indaiá seed oil performed in this work showed its high content of saturated fatty acids, lauric acid being the main one $(55.8 \%)$. Indaiá oil appeared to be very similar to babassu oil but contains less unsaturated fatty acids than this one (5.8 and $9.45 \%$, resp.). Indaiá oil could be cultivated as a new source of vegetable oil with potential for food and cosmetic industries, as is babassu oil.

\section{Acknowledgments}

The authors gratefully acknowledge FAPEMIG, CAPES, and $\mathrm{CNPq}$ for fellowships and financial support.

\section{References}

[1] J. C. Pintaud, "An overview of the taxonomy of Attalea (Arecaceae)," Revista Peruana de Biología, vol. 15, pp. 55-63, 2008.

[2] M. Galetti and J. C. Fernandez, "Palm heart harvesting in the Brazilian atlantic forest: changes in industry structure and the illegal trade," Journal of Applied Ecology, vol. 35, no. 2, pp. 294301, 1998.

[3] C. E. Steffler, C. I. Donatti, and M. Galetti, "Predation of Attalea dubia (Arecaceae) in an island in the Atlantic Rainforest of Brazil," Palms, vol. 52, pp. 133-140, 2008.

[4] M. A. Teixeira, "Babassu—a new approach for an ancient Brazilian biomass," Biomass and Bioenergy, vol. 32, no. 9, pp. 857864, 2008.
[5] D. Firestone, Official Methods and Recommended Practices of the American Oil Chemists' Society, American Oil Chemists' Society, Champaign, Ill, USA, 3rd edition, 1998.

[6] AOCS Official Method Ce 2-66, Preparations of Methyl Esters of Fatty Acids, American Oil Chemists' Society, Champaign, Ill, USA, 1997.

[7] G. Knothe and J. A. Kenar, "Determination of the fatty acid profile by ${ }^{1} \mathrm{H}-\mathrm{NMR}$ spectroscopy," European Journal of Lipid Science and Technology, vol. 106, no. 2, pp. 88-96, 2004.

[8] A. Barison, C. W. P. da Silva, F. R. Campos, F. Simonelli, C. A. Lenz, and A. G. Ferreira, "A simplemethodology for the determination of fatty acid composition in edible oils through ${ }^{1} \mathrm{H}$ NMR spectroscopy," Magnetic Resonance in Chemistry, vol. 48, no. 8, pp. 642-650, 2010.

[9] N. Vlachos, Y. Skopelitis, M. Psaroudaki, V. Konstantinidou, A. Chatzilazarou, and E. Tegou, "Applications of Fourier transform-infrared spectroscopy to edible oils," Analytica Chimica Acta, vol. 573-574, pp. 459-465, 2006.

[10] B. S. Ferreira, C. G. de Almeida, L. P. Faza et al., "Comparative properties of amazonian oils obtained by different extraction methods," Molecules, vol. 16, no. 7, pp. 5874-5885, 2011.

[11] N. Gotoh and S. Wada, "The importance of peroxide value in assessing food quality and food safety," Journal of the American Oil Chemists' Society, vol. 83, no. 5, pp. 473-474, 2006.

[12] E. Akbar, Z. Yaakob, S. K. Kamarudin, M. Ismail, and J. Salimon, "Characteristic and composition of Jatropha curcas oil seed from Malaysia and its potential as biodiesel feedstock feedstock," European Journal of Scientific Research, vol. 29, no. 3, pp. 396-403, 2009.

[13] M. D. Guillén and N. Cabo, "Fourier transform infrared spectra data versus peroxide and anisidine values to determine oxidative stability of edible oils," Food Chemistry, vol. 77, no. 4, pp. 503-510, 2002. 


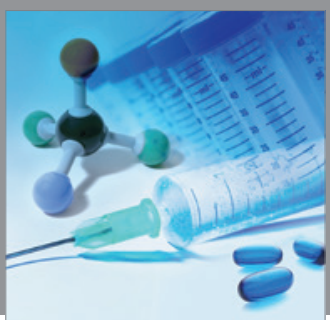

International Journal of

Medicinal Chemistry

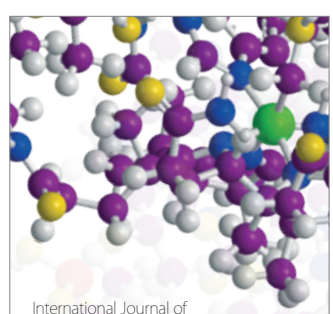

Carbohydrate Chemistry

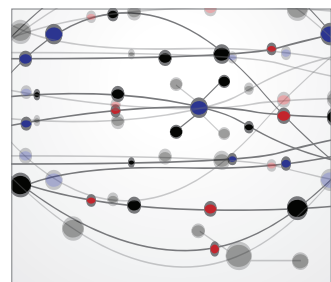

The Scientific World Journal
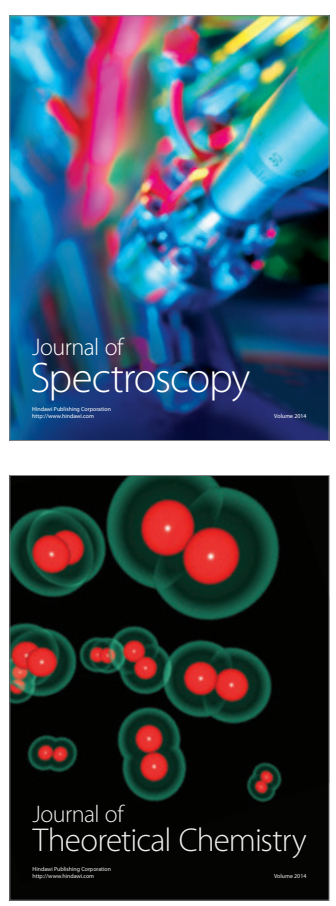
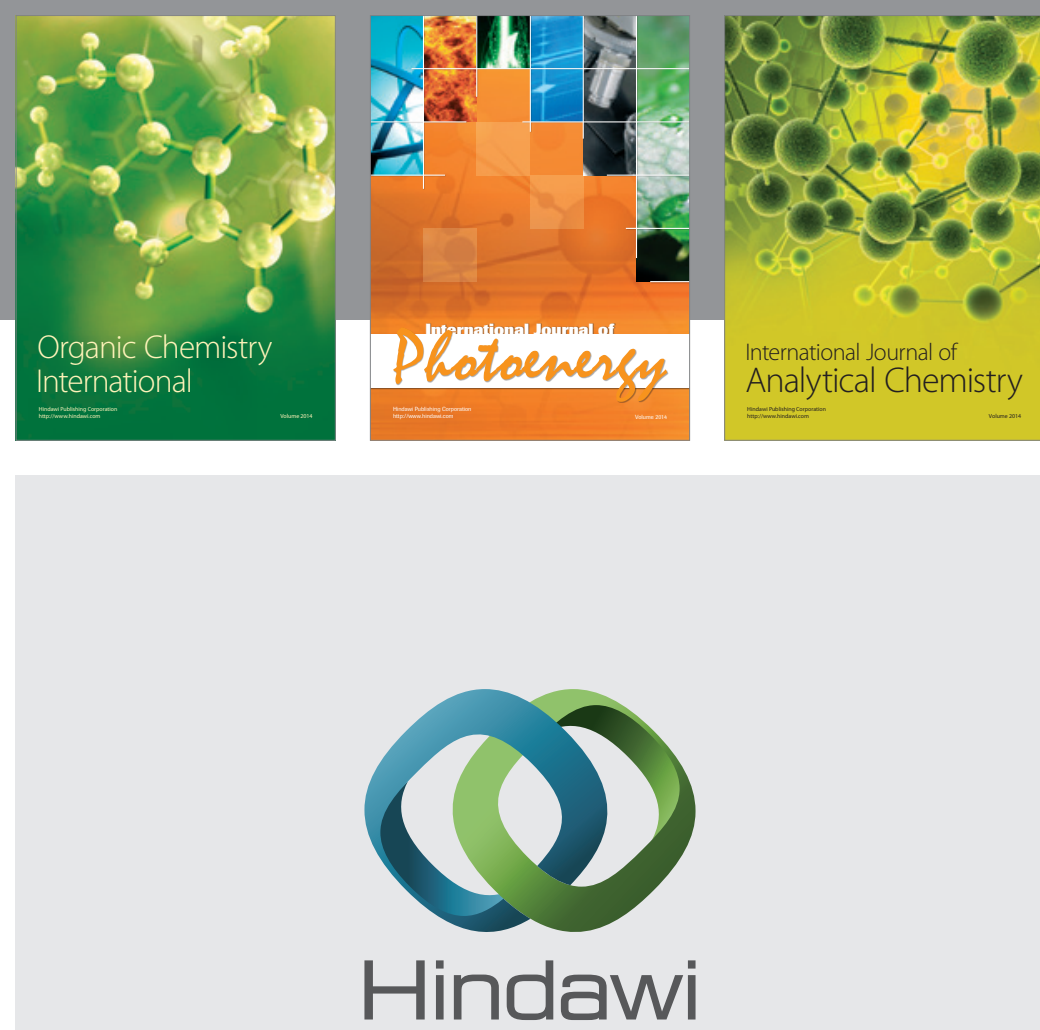

Submit your manuscripts at

http://www.hindawi.com
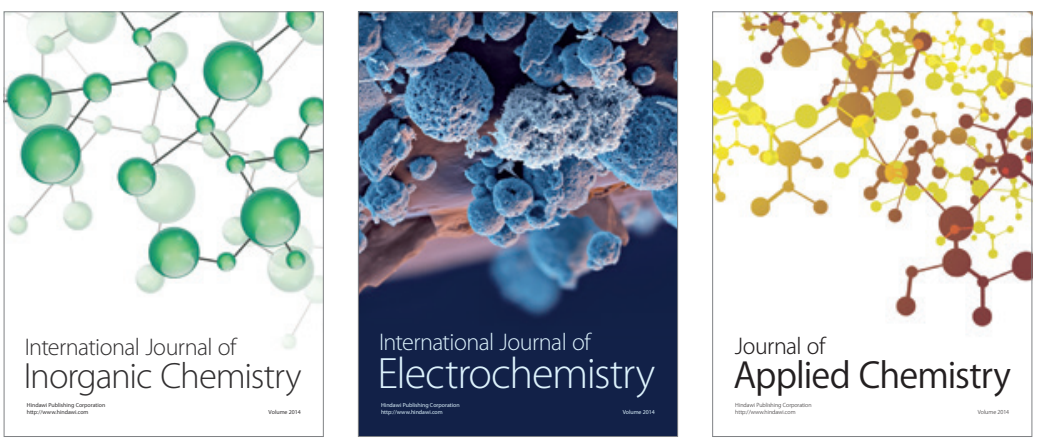

Journal of

Applied Chemistry
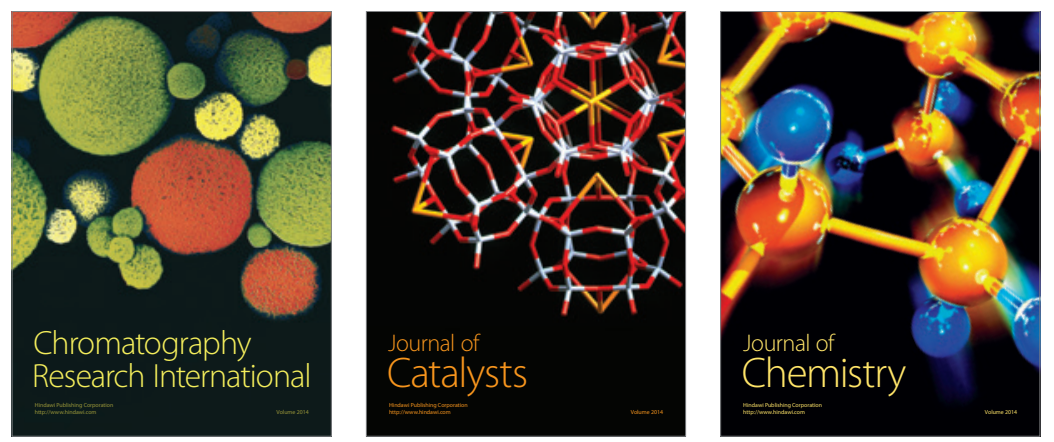
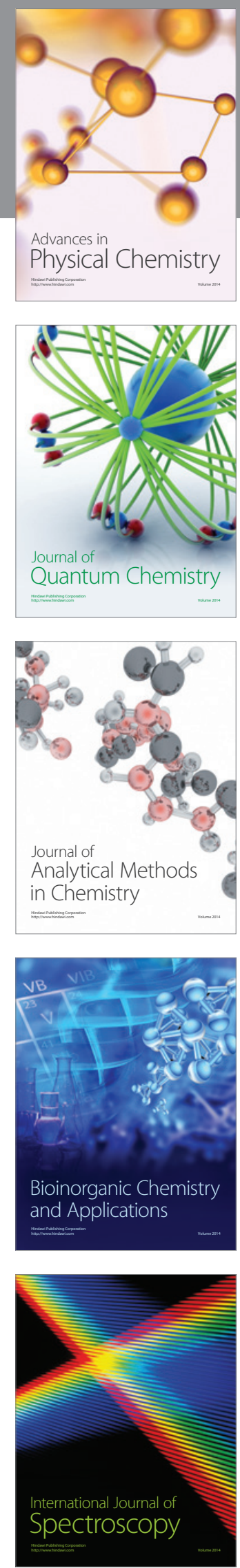